\title{
A Case of Free-Floating Endolymph Particle Found during Transmastoid Posterior Semicircular Canal Occlusion for Intractable Posterior Canal Benign Paroxysmal Positional Vertigo
}

\author{
Ji-Su Park, Seung-Hun Lee, Yong-Ho Park, and Jin Woong Choi \\ Department of Otorhinolaryngology-Head and Neck Surgery, School of Medicine, Chungnam National University, Daejeon, Korea
}

\author{
난치성 발작성두위현훈 치료를 위해 시행한 후반고리관폐쇄술 중 발견된 유리 부유물 1예 \\ 박지수 · 이승훈 · 박용호 · 최진웅 \\ 충남대학교 의과대학 이비인후-두경부외과학교실
}

\author{
Received November 11, 2015 \\ Revised December 18, 2015 \\ Accepted January 13, 2016 \\ Address for correspondence \\ Jin Woong Choi, MD, PhD \\ Department of Otorhinolaryngology- \\ Head and Neck Surgery, \\ School of Medicine, \\ Chungnam National University, \\ 282 Munhwa-ro, Jung-gu, \\ Daejeon 35015, Korea \\ Tel $+82-42-280-7694$ \\ Fax +82-42-253-4059
}

E-mail choijw@cnu.ac.kr
Benign paroxysmal positional vertigo (BPPV) is a common inner ear cause of vertigo, most of which can be treated by particle repositioning maneuver (PRM). However, in rare cases, positional vertigo could persist or frequently recur after several PRM. In these intractable cases, surgical treatments including singular neurectomy and semicircular canal occlusion have been used. Posterior semicircular canal occlusion has some advantages over singular neurectomy in hearing preservation and feasible surgical technique. Also free-floating endolymph particles causing intractable BPPV are known to occur in about $20 \%$ of the cases during canal occlusion surgery. Nevertheless, to the best of our knowledge, there has not been any report on the identification of those particles in the Korean literature. In this paper, we report a case of freefloating endolymph particle found during transmastoid posterior semicircular canal occlusion for intractable posterior canal BPPV.

Korean J Otorhinolaryngol-Head Neck Surg 2016;59(7):537-41

Key Words Benign paroxysmal positional vertigo · Intractable vertigo

Semicircular canal occlusion.

\section{서 론}

양성발작성두위현훈은 어지럼을 유발하는 내이 질환 중에 가장 흔한 빈도를 보이는 질환으로 난형낭반에서 빠져나온 이석이 반고리관 내를 부유하거나 팽대부릉에 부착하여 머 리를 움직일 때마다 내림프액의 흐름과 팽대부릉정의 위치변 화를 야기하여 회전성의 어지럼증을 느끼게 된다. ${ }^{1)}$ 발병 시에 는 심한 어지럼증을 호소하나 이석을 난형낭으로 재배열시키 는 다양한 이석치환술이나 미로 내의 이석을 흩어지게 하는 습관화 운동을 통해 $90 \%$ 이상의 환자에서 증상의 호전을 보 인다고 알려져 있다.,3) 하지만 일부에서는 수시로 재발을 하거
나 이석치환술에도 효과를 보이지 않는 경우도 있다. 이와 같 이 반복적인 이석치환술에도 현훈이 지속되는 경우를 난치성 발작성두위현훈(intractable paroxysmal positional vertigo)이 라고 정의하고 이러한 경우 수술적 치료를 고려해볼 수 있다. ${ }^{4}$

난치성 발작성두위현훈의 수술적 치료에는 팽대부신경절 제술(ampullary nerve transection)이나 반고리관폐쇄술(semicircular canal occlusion)이 있다.5,6) 양성발작성두위현훈 중 가장 빈도가 많은 후반고리관 양성발작성두위현훈의 경 우 후반고리관폐쇄술이 후팽대부신경절제술보다 수술이 비 교적 용이하고 수술 후 청력 감소의 빈도가 적다고 알려져 있 다. ${ }^{4)}$ 후반고리관폐쇄술을 시행하는 경우 거의 모든 경우에서 
술 후 회전성 어지럼증이 호전되는 것으로 보고되고 있는데, Parnes와 McClureㄱㄴ는 1992년 처음으로 수술 중 발견된 유 리 부유물을 보고하였다.

그러나 국내에는 아직 수술 중 발견된 유리 부유물에 대한 보고가 없어 저자들은 후반고리관에서 발생한 난치성 발작 성두위현훈을 치료하기 위해 후반고리관폐쇄술을 시행한 환 자에서 수술 중 후반고리관 내에서 유리 부유물을 관찰하였 기에 문헌고찰과 함께 보고하는 바이다.

\section{증 례}

69세 남자 환자가 반복적으로 재발하는 어지럼증을 주소로 내원하였다. 7개월 전 오전에 일어나려는데, 회전성의 어지럼 증이 수 초 정도 발생하여 개인의원에서 우측 후반고리관 양 성발작성두위현훈으로 진단받고 이석치환술을 시행받았다. 그러나 이후에도 반복하여 증상이 발생하여 7개월에 걸쳐 약 12차례 이상의 이석치환술 및 Brandt-Daroff 습관화 치료를 시행하였는데도 불구하고 일상생활에 어려움을 호소할 정도 의 어지럼증이 반복적으로 발생하여 내원하였다. 이경검사에 서 고막 및 외이도에 이상소견은 없었고 청력검사에서 우측
$43 \mathrm{~dB} \mathrm{HL}$, 좌측 $45 \mathrm{~dB} \mathrm{HL}$ (6분법)의 감각신경성 난청이 있었 다. 시행한 Dix-Hallpike 검사에서 우측으로 눕힐 때 상방 및 시계방향의 회전성 안진이 관찰되어, 이전과 동일한 우측 양 성발작성두위현훈으로 진단하고, 이석치환술을 시행하였는 데, 증상이 호전되어 경과 관찰하였다. 시행한 측두골 단층촬 영영상과 자기공명영상에서 특별한 이상소견은 없었다. 그 후 수차례 같은 증상으로 내원하였고 내원 시마다 시행한 DixHallpike 검사에서 우측 상방 및 시계방향의 회전 안진이 관 찰되어 후반고리관의 재발형 난치성 발작성두위현훈으로 판 단하여 후반고리관 폐쇄술을 시행하기로 하였다.

전신마취하에 유양돌기삭제술을 시행하였고(Fig. 1A) 후 반고리관의 골성 미로를 노출시킨 후 $1 \times 4 \mathrm{~mm}$ 크기로 골내 막을 노출시킨 후 충분한 세척을 통하여 주변의 골편들을 제 거하고 골성 미로에 창을 만들었다(Fig. 1B). 창을 개방한 후 내림프 내부의 유리 부유물을 확인할 수 있었다(Fig. 1C). 유 양돌기삭제술을 시행할 때 채취한 dry bone dust와 fibrinogen glue를 이용하여 만든 bone pate를 이용하여 후반고리 관을 폐쇄한 후(Fig. 1D) 수술을 마쳤다. 특히 관찰된 유리 부유물이 시간이 지남에 따라 후반고리관의 팽대부 쪽으로 이동하는 것을 관찰할 수 있어 난치성 발작성두위현훈의 원
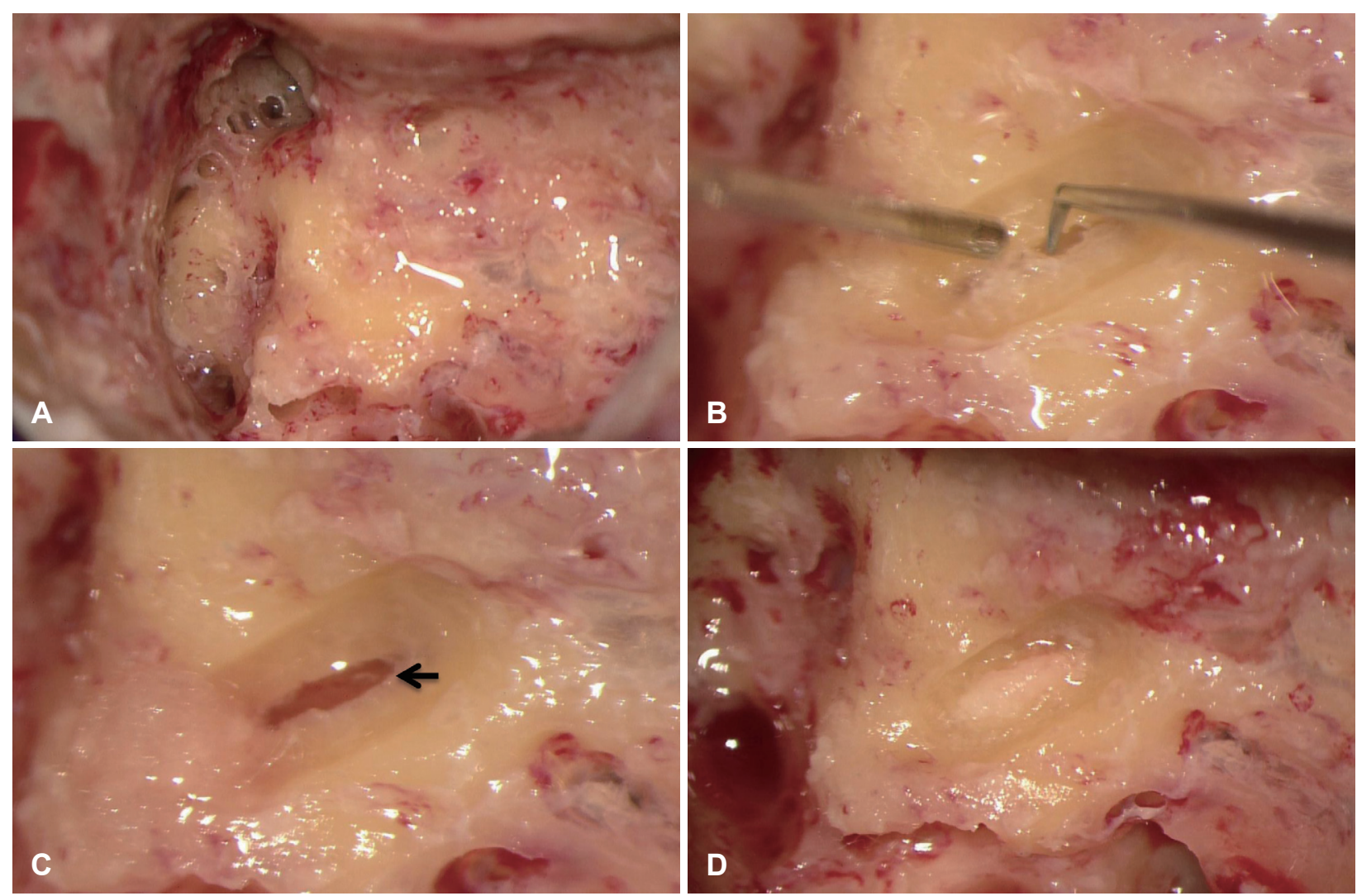

Fig. 1. Surgical procedures of transmastoid posterior semicircular canal occlusion. Exposure posterior semicircular canal after complete mastoidectomy (A). Fenestration of posterior semicircular canal with micro-instruments (B). Free-floating endolymph particle in endolymph (arrow) (C). Posterior canal occlusion using dry bone chips and fibrinogen glue (D). 
인이 되는 이석(otolith)임을 확인할 수 있었다(Fig. 2).

수술 후 환자는 경도의 평형장애(dysequilibrium)를 호소하 였으나 Dix-Hallpike 검사에서 우측으로 향하는 회전성 안진 이 사라진 것을 확인할 수 있었다. 수술 후 1주일째 주관적인 증상도 많이 호전되어 퇴원 후 외래 경과관찰 중에 있고, 수 술 후 시행한 청력검사에서 청력감소 없이 수술 전 청력이 유 지되는 것을 확인할 수 있었다(Fig. 3).

\section{고 찰}

양성발작성두위현훈은 어지럼을 유발하는 가장 흔한 원인
중 하나로 어지럼증 환자의 17 37\%까지 다양하게 보고되고 있다. ${ }^{8,9)}$ 대부분의 경우 이석치환술을 통해 증상 호전을 보이 지만 소수에서는 반복되는 치료에도 증상이 지속되는데 일 반적으로 1 년 이상 지속되면서 환자의 생활에 장애를 초래 하는 경우를 난치성 발작성두위현훈이라고 정의한다. ${ }^{1)}$ 난치 성 발작성두위현훈은 두 가지 아형으로 구분할 수 있는데 반 복되는 치료에도 변화없이 증상이 지속되는 경우를 만성형 으로, 호전과 재발을 반복하는 경우를 재발형으로 분류할 수 있다. ${ }^{10)}$ 일반적으로 $1 \%$ 미만의 환자에서 난치성의 양상을 보인다고 보고하며 이러한 경우에 수술적 치료로 증상의 호 전을 기대할 수 있다. ${ }^{4)}$ 많은 보고에서 1년 이상 증상이 지속
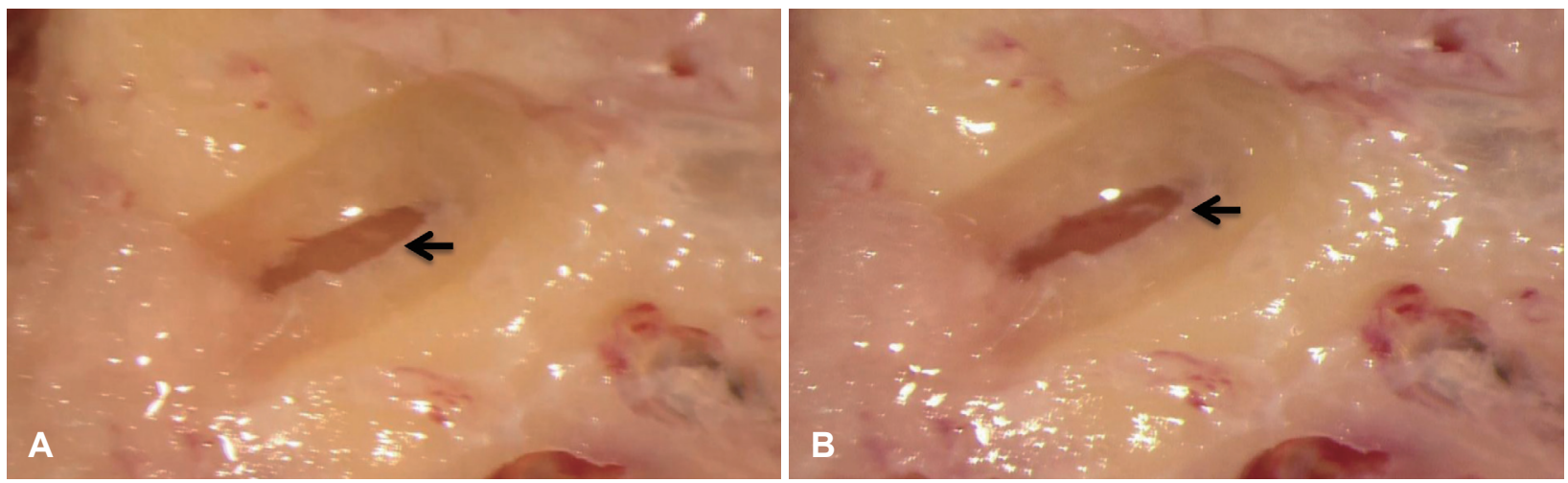

Fig. 2. Free-floating particle in endolymph. Whitish small fragment was seen (A, arrow) and it moves freely toward posterior canal ampulla with the time (B, arrow).
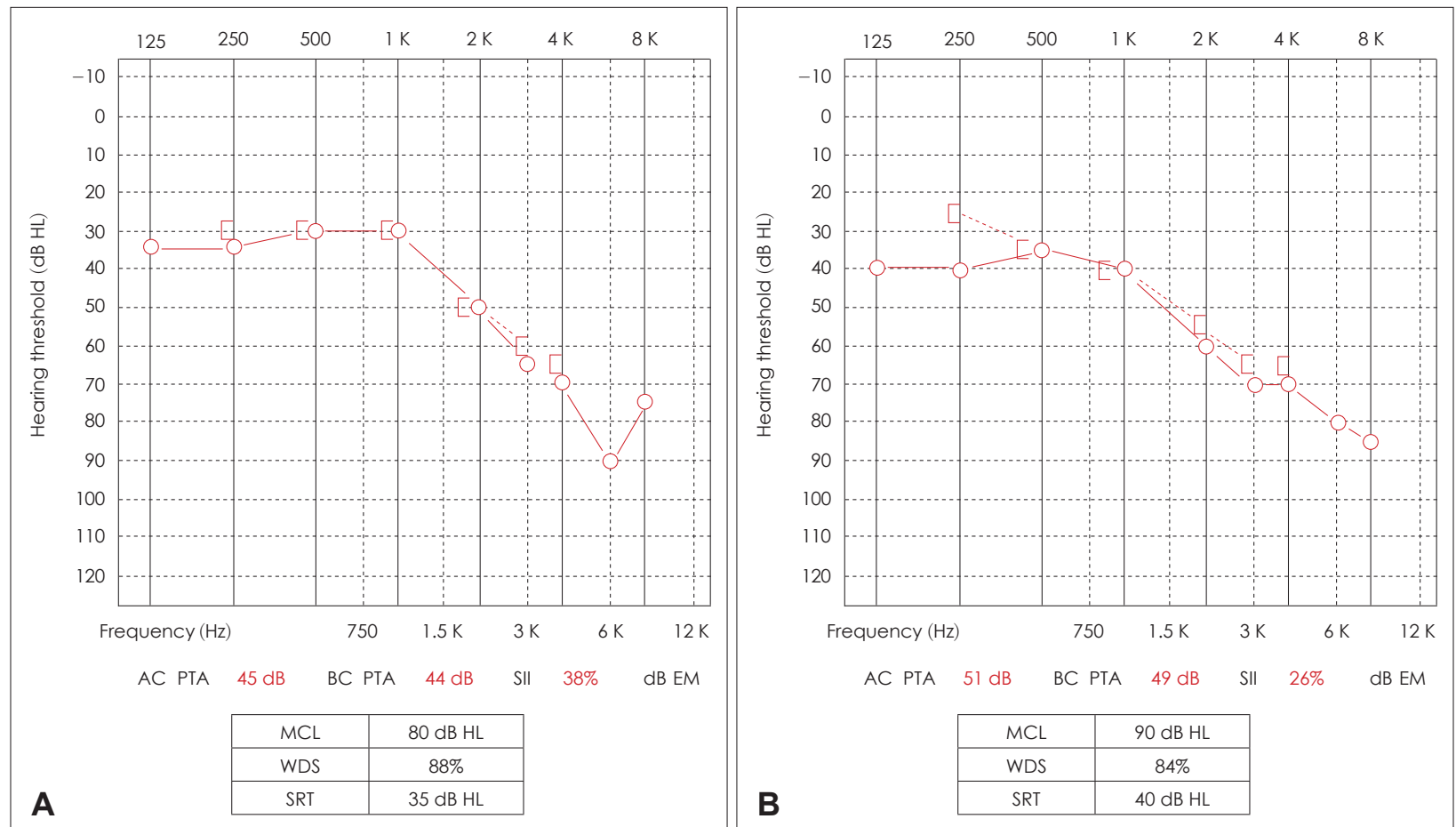

Fig. 3. Pre- and postoperative hearing. Preoperative mean hearing threshold was $43 \mathrm{~dB} \mathrm{HL}$ (A). There was no significant change of the threshold after posterior semicircular canal occlusion (B). MCL: most comfortable loudness, WDS: word discrimination score, SRT: speech reception threshold. 
되는 경우를 난치성으로 간주하고 수술적 치료를 시행한다 고 보고하지만, 일부에서는 3 개월 이상 증상이 지속되는 경 우에 수술을 고려하기도 하고 증상의 기간보다는 환자의 상 태에 따라 수술을 결정해야 한다고 주장한다. ${ }^{11}{ }^{1}$ 본 증례의 경 우도 다수의 이석치환술과 습관화 운동을 시행하였는데도 불구하고 약 7 8개월가량 반복적으로 발생하는 재발형의 양상을 보였다.

수술적 치료는 $\mathrm{Gacek}^{5)}$ 에 의해 처음 보고된 후팽대부신경 절제술(singular neurectomy)과 Parnes와 $\mathrm{McClure}{ }^{6}$ 에 의해 처음 보고된 반고리관폐쇄술(semicircular canal occlusion)이 주로 사용되는데 반고리관폐쇄술은 후팽대부신경절제술에 비해 청력 및 술기에 대한 장점을 가지고 있다. ${ }^{4)}$ 많은 연구에 서 술 후 대부분의 경우에 회전성 어지럼증이 호전된다고 보 고하고 있고, 일시적인 감각신경성 난청은 비교적 흔하게 발 생하나 시간의 경과에 따라 호전되며 영구적인 청력감소는 $5 \%$ 미만으로 비교적 드문 것으로 알려져 있다.1,12) 본 증례의 환자도 수술 직후 상방 및 시계방향의 안진이 소실됨을 비디 오 안진검사에서 확인할 수 있었고 환자의 체위성 어지럼증 도 수술 직후 바로 호전되었다. 약 2주 정도의 평형이상(dysequilibrium)을 호소하였지만 그 이후 호전되어 일상적인 생 활에 지장이 없었으며 수술 후 청력도 변화를 보이지 않아 성공적으로 치료가 되었다.

Beyea 등은 난치성 benign paroxysmal positional vertigo 로 후반고리관 페쇄술을 시행한 65 예 중에 약 20\%에서 유리 부유물을 발견하였다고 보고하였다. 그러나 Kisilevsky 등 ${ }^{2)}$ 은 수술한 모든 경우에서 유리 부유물을 발견하지 못하였고, 이것은 반고리관의 팽대부 쪽에 이석이 존재하거나 수술 당 시에 이석이 반고리관에 존재하지 않을 수 있으며, 한편으로 는 양성발작성두위현훈이 기계적인 원인보다는 신경학적인 원인에 의해 발생하였을 가능성에 대해서도 추측해 볼 수 있 다고 주장하였다. 국내에서도 아직 후반고리관폐쇄술을 시행 하는 도중 유리 부유물을 발견하였다는 보고는 없었다. 본 증례의 경우에는 후반고리관을 개방하였을 때 유리 부유물 을 발견할 수 있었고, 부유물이 환자 수술 체위를 변경하는 중에 이동되는 것이 관찰되어 난치성 발작성두위현훈이 이 부유물에 의해 발생한 것임을 확인할 수 있었다(Fig. 2).

후반고리관폐쇄술은 반고리관의 골성미로에 창을 만든 후 내림프의 움직임을 막음으로써 증상의 발생을 방지하는 술 법으로 내림프의 움직임을 막기 위해 다양한 폐쇄물질들이 사용될 수 있다. 수술 중 채취한 골편과 인공 접착제를 사용 하여 만든 bone pate가 가장 많이 사용되지만 골막이나 근 막을 이용할 수도 있다. ${ }^{13)}$ 최근에는 몇몇 연구들에서 레이저 를 이용한 폐쇄가 기계적 폐쇄와 비슷한 성공률을 보인다고
주장하였고 ${ }^{14)}$ Antonelli 등 ${ }^{15}$ 의 연구에서는 $\mathrm{CO}_{2}$ 레이저를 이 용한 경우에 술 후 어지럼증의 호소가 적었다고 보고하였으 나 효과에 대해서는 아직 논란이 있는 것으로 생각된다.

Parnes와 McClure는 유리 부유물이 발견된 환자는 그렇 지 않은 경우보다 비교적 고령이었다는 점에서 연령에 따른 활동성 결여가 부유물의 자연치환을 막았을 것이며, 이로 인 해 수술 중 유리 부유물을 발견할 수 있었을 것이라고 추측하 였다. 하지만 수술 후 모든 환자에서 체위성 어지럼증이 호전 된 것으로 보아 유리 부유물의 발견 유무와 예후는 특별한 관 계는 없을 것으로 생각된다. 난치성 발작성두위현훈의 빈도가 매우 적고 또한 수술적인 치료까지 시행되는 경우는 드물기 때문에 현재까지 증례보고에 머무르고 있는 실정으로 유리 부유물이 발견될 수 있는 인자나 이것이 치료에 미치는 영향 에 대해서는 좀 더 연구가 필요할 것으로 사료된다.

난치성 발작성두위현훈은 후반고리관폐쇄술을 통하여 성 공적으로 치료할 수 있으며, 일부에서는 원인이 되는 유리 부 유물을 확인함으로써 정확한 진단을 할 수 있으므로 수술을 시행함에 있어 조심스러운 접근과 세심한 관찰이 필요할 것 으로 생각된다.

\section{REFERENCES}

1) Beyea JA, Agrawal SK, Parnes LS. Transmastoid semicircular canal occlusion: a safe and highly effective treatment for benign paroxysmal positional vertigo and superior canal dehiscence. Laryngoscope 2012; 122(8):1862-6.

2) Epley JM. Positional vertigo related to semicircular canalithiasis. Otolaryngol Head Neck Surg 1995;112(1):154-61.

3) Semont A, Freyss G, Vitte E. Curing the BPPV with a liberatory maneuver. Adv Otorhinolaryngol 1988;42:290-3.

4) Leveque M, Labrousse M, Seidermann L, Chays A. Surgical therapy in intractable benign paroxysmal positional vertigo. Otolaryngol Head Neck Surg 2007;136(5):693-8.

5) Gacek RR. Transection of the posterior ampullary nerve for the relief of benign paroxysmal positional vertigo. Ann Otol Rhinol Laryngol 1974;83(5):596-605.

6) Parnes LS, McClure JA. Posterior semicircular canal occlusion for intractable benign paroxysmal positional vertigo. Ann Otol Rhinol Laryngol 1990;99(5 Pt 1):330-4.

7) Parnes LS, McClure JA. Free-floating endolymph particles: a new operative finding during posterior semicircular canal occlusion. Laryngoscope 1992;102(9):988-92.

8) Nedzelski JM, Barber HO, Mcllmoyl L. Diagnoses in a dizziness unit. J Otolaryngol 1986;15(2):101-4.

9) Bath AP, Walsh RM, Ranalli P, Tyndel F, Bance ML, Mai R, et al. Experience from a multidisciplinary “dizzy” clinic. Am J Otol 2000;21 (1):92-7.

10) Schuknecht HF. Cupulolithiasis. Arch Otolaryngol 1969;90(6):765-78.

11) Zappia JJ. Posterior semicircular canal occlusion for benign paroxysmal positional vertigo. Am J Otol 1996;17(5):749-54.

12) Kisilevsky V, Bailie NA, Dutt SN, Rutka JA. Lessons learned from the surgical management of benign paroxysmal positional vertigo: the University Health Network experience with posterior semicircular canal occlusion surgery (1988-2006). J Otolaryngol Head Neck Surg 2009;38(2):212-21. 
13) Parnes LS. Update on posterior canal occlusion for benign paroxysmal positional vertigo. Otolaryngol Clin North Am 1996;29(2):333-42.

14) Lin SZ, Fan JP, Sun AH, Guan J, Liu HB, Zhu QB. Efficacy of laser occlusion of posterior semicircular canal for benign paroxysmal positional vertigo: case report. J Laryngol Otol 2010;124(5):e5.

15) Antonelli PJ, Lundy LB, Kartush JM, Burgio DL, Graham MD. Mechanical versus $\mathrm{CO} 2$ laser occlusion of the posterior semicircular canal in humans. Am J Otol 1996;17(3):416-20. 